\title{
Improvement of Innovative Infrastructure as a Means of Economic Development
}

\author{
Alla Nikonorova \\ Department of Management and Marketing \\ Moscow Witte University \\ Moscow, Russia \\ nikonorova-av@mail.ru \\ Natalia Isaichykova \\ Sukhoi State Technical University of Gomel \\ Gomel, Republic of Belarus \\ natalyii@mail.ru
}

\author{
Dmitry Morkovkin \\ Department of Economic Theory \\ Financial University under the Government \\ of the Russian Federation \\ Moscow, Russia \\ MorkovkinDE@mail.ru \\ Valery Nezamaikin \\ Russian State University for the Humanities \\ Moscow, Russia \\ NezamaikinVN@mail.ru
}

\begin{abstract}
The article examines the effective introduction of innovations into practice and their influence on the improvement of infrastructure and economic growth in the region. Presently, the lack of proper mechanisms and of organizational regulations in the field of innovative infrastructure improvement hampers the process of sustainable development. New technologies for the immediate usage of information are required. The techniques for development and implementation of a permanent innovations monitoring system are considered and proposed in the article. A model of permanent improvement of an innovative infrastructure is developed and presented. Its usage can facilitate and expedite the process of implementation of innovations and growth in economic activity in a region.
\end{abstract}

Keywords-management; innovative development; monitoring of innovations; decision making management; innovative infrastructure; innovative process

\section{INTRODUCTION}

Active development of innovative infrastructure depends on the prompt introduction of innovations; however, their search and elaboration is a complex task that requires considerable effort. Systematic work on the development of a system of innovations searches can significantly increase the effectiveness of innovative infrastructure. Information and other innovations have changed the productive forces of society and led to their significant growth. Improvement of innovation infrastructure became the catalyst for rapid development of various industries and fields of activity.

Industries and companies, which rapidly implement advanced ideas, gain a significant competitive advantage in the market under the present conditions of vigorous technological changes. This situation becomes even more acute in the context of globalization. However, not only the implementation but also the actual search for information about new developments takes a long period of time.
Generally, new innovative technologies take their basis from existing knowledge. The application of existing and previously tested knowledge can be quite rational and justified. Competitive advantages of the most successful companies are often based on new knowledge; but the innovations derived from new knowledge are accompanied by high costs and risks, which may significantly hamper the production of knowledge and the reduce level of satisfaction with innovation by economic agents [1]. The process of introducing new knowledge into practice is also a very risky procedure. The decision about the introduction of an innovation should always be based on detailed analysis of a particular situation.

Active implementation of information technologies opens new possibilities for further development. The emergence and active use of various communication tools can significantly speed up management processes. The process of searching for and the analysis of new ideas can be alleviated to some extent by its formalization. The implementation of information technology is opening up immense opportunities for business development and helping boost the efficiency of activities undertaken [2].

The model described in this article aims to reduce these obstacles. Its implementation contributes by generating ideas about the ways of innovative infrastructure improvements, and creates conditions for their realization. Currently, vast amounts of information is available. Its analysis and understanding becomes almost impossible, even for the combined efforts of many employees of huge companies. This fact accentuates the importance of the matters considered in this article. 


\section{METHODOLOGICAL ASPECTS OF INNOVATIVE INFRASTRUCTURE IMPROVEMENT}

In the process of conducting this research, the authors analyzed statistical data and patent letters, and reached a conclusion about the necessity for the development and implementation of a system capable of accelerating innovations implementation in the activities of entities which form the innovative infrastructure of a region.

The definition of "innovative infrastructure" is given in the Federal law on science and state scientific and technical policy of August 23, 1996, № 127-FZ. Innovative infrastructure is defined in this law as a set of entities contributing to the implementation of innovative projects, including provisions for administrative, logistical, financial, information, personnel, consulting, and organizational services. Another well known definition, which can be found in works of numerous authors, is the following: innovative infrastructure is a set of innovation agents (research institutes, institutions of higher education, innovation and technological centers, technological parks, special economic zones, centers and funds of development, and other specialized organizations), resources, and funds, providing logistical, financial, organizational, methodological, informational, consulting, and other service innovation [3].

Due to the specifics of the theme, it attracts the attention of scientists in multiple areas. Specialists in the field of computer science played the basic role in forming techniques for searching for information. Significant contributions in development of search technologies were made by such researchers as Gerard Salton, Vannevar Bush, Sergey Brin, Larry Page, Marc Lowell Andreessen, and Tim Berners-Lee. The use of information technologies, penetrating into all spheres of society, has a positive effect on the economic performance of organizations. They have become an integral component in management processes.

Among the researchers who have made significant contribution in the development of control systems and search systems, it is necessary to acknowledge I. Ansoff, G.N. Fedorova, and V. M. Glushkov. The work of E.E. Sharco, S.E. Eroshina, I.A. Ivanova, and E.V. Trushkin were dedicated to studying the specifics of creating monitoring systems.

Innovative activity by business entities can be formed through the production and implementation of economic, technological, organizational, social, and other innovations, which help to obtain competitive advantages, and lead to direct and/or indirect economic benefits. In their activities, increasing numbers of domestic organizations apply information posted on global information networks. Analysis of the data presented in "Table I" shows the number of organizations using global information networks is still increasing [4].

TABLE I. TABLE 1. SHARE OF RUSSIAN ORGANIZATIONS USING GLOBAL INFORMATION NETWORKS

\begin{tabular}{|l|l|l|l|l|l|l|l|l|l|l|l|}
\hline \multicolumn{10}{|c|}{ Organizations using global information network } \\
\hline Years & 2005 & 2006 & 2007 & 2008 & 2009 & 2010 & 2011 & 2012 & 2013 & 2014 & 2015 \\
\hline Total & 54,3 & 62,5 & 68,7 & 74,7 & 79,3 & 83,4 & 85,6 & 87,5 & 88,7 & 89,8 & 89,0 \\
\hline
\end{tabular}

The information presented in Table 1 was obtained from the form of Federal statistical observation, № 3-inform "Data about the usage of information and communication technologies, computer engineering, software, and services in these areas." Clearly, despite of the huge amount of work done in the creation of effective search systems, refinement of the new techniques is still required.

A special problem of the present period of the country's development is the encouragement of high growth rates of the gross domestic product, the further improvement of production efficiency, and the achievement, on the basis of these factors, a high level of standard of living for the population [5]. Development of innovation infrastructure provides a comprehensive positive impact on the conditions in a region; it contributes to the acceleration of production processes, has a positive effect on environmental situations, and creates conditions for improving the population's quality of life.

The introduction of innovations is a result of extensive preliminary analysis. Its accomplishment requires considerable resources. Development and implementation of a system that facilitates the searching processes will help to reduce the amount of resources required. Such a system can be aimed at modernizing the quality of production processes, simplification of procedures for the implementation of new knowledge, simplification of procedures for the introduction of innovations, and an increase in the volume of work performed by the improvement of applied methods.

To obtain potentially useful information, it is necessary to determine the criteria of the search. The range of relevant data can be quite extensive. The task of employees is to determine what fields of infrastructure should be improved and, depending on their ability, to identify specific criteria for requests. The implementation of such activities can be facilitated by introducing a formalized system of information searches.

\section{CREATION OF THE MODEL OF INNOVATIVE INFRASTRUCTURE IMPROVEMENT}

Improvement of the innovation infrastructure has a practical orientation and is influenced by changes in the external environment. The continuity of the process of innovation is logical; it is caused with a number of factors. These can include improvement of technological processes, diffusion of innovations, and the development and implementation of information technology [6]. The core idea for the search is to be formed on the basis of determination of the main purpose of the project, such as improvement of conditions for new inventors or the process of participation in "technological platforms".

"Technological platforms" will become an important tool for the formation of the national system of innovations 
within the framework of public and private partnership between the state, business, and science [7] [8]. The construction of infrastructure has traditionally had a large public sector component [9]. The distinction between the innovation motives of scientists and producers is evidenced by a clear difference in the types of innovations they developed. Scientists tend to develop innovations that enabled the instruments to do qualitatively new types of things for the first time. Such functions might have been of interest only to the innovators themselves, or to some small fraction of the market. In contrast, manufacturers tended to develop innovations that made an instrument more convenient and more reliable in general - attributes of at least some interest to all potential customers [10]. As a result, the contradictive interests supplement each other.

The process of infrastructure improvement can start with the following steps:

- Conducting a preliminary analysis to identify the most promising and demanded areas for infrastructure development;

- Determining potentially relevant technologies for the improvement of the infrastructure;

- Searching for similar successful existing projects;

- Searching for unusual but potentially applicable innovations for the development of infrastructure ideas.

To ensure a positive quality of the proposed system, it is necessary to monitor its orientation following adaptation to specific goals and objectives of an entity.

The model of innovative infrastructure improvement can be described as a sequence of the following stages:

- Determination of the direction of innovative infrastructure development;

- Determination of specific fields for search;

- Specify the criteria for searching;

- Determination of the possible ways for improvement;

- Commencing the search process;

- Storage of potentially required data;

- Data analysis;

- Further analysis of selected data concerning its compliance with the basic strategy of the entity;

- Drafting the proposal for future implementation of the selected ideas;

- Creating specific plans;

- Implementation of the plans;

- Project realization;

- Feedback from the parties engaged in the project;

- Control evaluation (comparison of plans with results);
- Adjustment of the project on the basis of the received information.

It is rational to create a special system that is to perform on a regular or continual basis to search for potentially useful concepts in the development of innovations information. Such information for analysis may be collected from various sources located primarily in open access resources. The use of innovative technologies allows reducing the consumption of resources and improving the quality of the implemented processes. Their continuous optimization is now recognized as a trend in the field of management systems implementation.

\section{CONCLUSION}

Generating and searching for new ideas is a complicated task. To simplify the process of searching for and introducing innovations into a practical activity, the authors developed a method for the formation of a system for monitoring innovation. This system is to be used on a permanent basis. The whole system functions as a closed cycle, which can operate continuously.

The search for new knowledge is to be carried out continuously from open access resources. Information is to be searched for on the basis of predetermined sets of criteria; the data found is to be processed, filtered, and stored. It is important to create specialized tools to find and systematize information; this can be done with software dedicated to this purpose.

The information sought may relate to the field of activity of an entity both directly and indirectly. Based on the information obtained about the demands for innovations in existing infrastructure, it is possible to identify information that is of interest for further research and this can form the basis for future requests. Such strategic decision-making improves the quality of control systems functioning.

The proposed development's operation will simplify the procedures of searching for and implementation of new knowledge, expedite procedures of innovations implementation, enhance the volume of performed work, and improve accuracy in modeling by the advancement of applied methods. Despite the fact that the introduction of the proposed system does not completely exclude analytical work of experts, this can be significantly simplified through the introduction of formalized systems.

Active development of information technologies and their application in various fields create the preconditions for further growth. The innovations emerging in one area can often be effectively used in other areas. However, the identification of an innovation which is suitable for implementation in a specific field is a complex task, and the implementation may be carried out over a long period of time. The model presented in this article is aimed to resolve this problem. The opportunity for the practical application of information technologies in the improvement of innovative infrastructure acquires special value in the present circumstances. 
It is the authors' opinion that managers of Russian companies should pay more attention to the search for, analysis, processing, and implementation of innovations to strengthen their competitive position in the market. Their usage allows scheduling work within projects tasks, and managing a variety of actions. Additionally, the decisionmaking process can be greatly facilitated by the implementation of formalized systems [11].

The continuous search for innovations and the development of a system for their prompt implementation can become the basis for forming effective management systems in a region. The introduction of such models in practice creates conditions for generating new ideas, active dissemination of innovations, and improved economic efficiency in a region.

\section{REFERENCES}

[1] Improvement of mechanisms of increase of innovative activity of industrial enterprises. The collective monograph / Under the editorship of Veselovsky M. Y., Kirova I. V. - M.: Publishing house "Scientific consultant", 2017, p. 304.

[2] M. Y. Veselovsky, A.V. Nikonorova, A.A. Stepanov, N.L. Krasyukova, I.V. Bitkina, The development of innovative startups in Russia: the regional aspect // Academy of Strategic Management Journal. 2017. Vol. 16. № 1. pp. 197-208.

[3] A. V. Nikonorova. The usage of innovative technologies in the development of the region infrastructure // Intellekt. Innovatsii. Investitsii. 2017, No. 7, pp. 26-30.

[4] Federal State Statistics Service of the Russian Federation (2017) Science and Innovations. Retrieved October 20, 2017, from http://www.gks.ru/wps/wcm/connect/rosstat_main/rosstat/ru/statistics /science_and_innovations/science/\#

[5] N. V. Kiseleva, M.V. Panichkina, E.N. Klochko, A.V. Nikonorova, S.V. Kireev, Creation of clusters of small enterprises of the region // International Journal of Economics and Financial Issues, 2016, vol. 6. No S2. pp. 294-297.

[6] A.V. Nikonorova, Innovative development of logistics infrastructure of the Black Sea region and its ecological problems / Ecological and Environmental problems of modern society and ways for their solution: Materials of XIII international scientific conference, Moscow Witte University. 2017. pp. 380-388.

[7] I.S. Sandu, N.E. Ryzhenkova, M.Y. Veselovsky, A.Y. Solovyov, Economic aspects of innovation-oriented market economy formation // Life Science Journal. 2014, vol. 11, No. 12, pp. 242-244.

[8] D. E. Morkovkin, Challenges and priorities of financing innovative development of the real economy sector // Bulletin of Financial University. 2015. No 6 (90), pp. 39-49.

[9] D. Canning, E. Bennathan, The Social Rate of Return on Infrastructure Investments. World Bank Policy Research Working Paper No. 2390. Available at SSRN: https://ssrn.com/abstract $=630763$

[10] E. von Hippel. Free innovation. - Cambridge, MA : MIT Press, 2016, p. 228.

[11] A.V. Nikonorova, Development and management of monitoring system innovation // Konkurentosposobnost v globalnom mire: ekonomika, nauka, tehnologii. 2017, No.4-4 (40), pp. 106-110. 